\title{
Investigation of the reaction kinetics of isolated Lewis acid sites in Beta zeolites for
}

the Meerwein-Ponndorf-Verley reduction of methyl levulinate to $\gamma$-valerolactone

Helen Luo, Daniel Consoli, William Gunther, Yuriy Román-Leshkov*

Department of Chemical Engineering, Massachusetts Institute of Technology, Cambridge,

$$
\text { MA } 02139
$$

*Corresponding Author: yroman@ @it.edu; Phone: (+1) 617-253-7090

\section{Graphical Abstract}

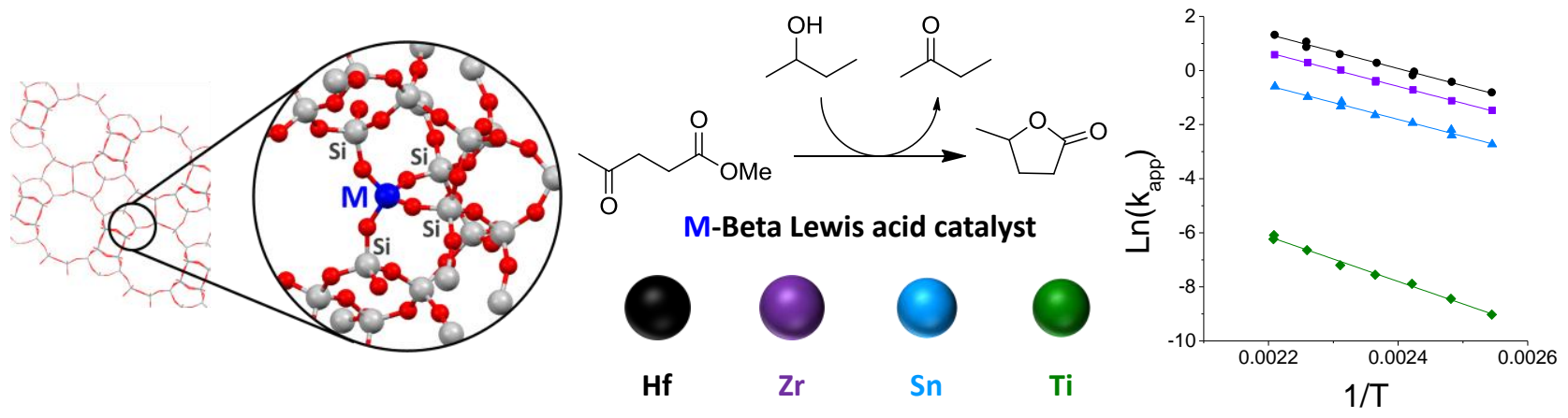




\begin{abstract}
We investigate the reaction kinetics of the Meerwein-Ponndorf-Verley (MPV) reduction of methyl levulinate (ML) to 4-hydroxypentanoates and subsequent lactonization to $\gamma$-valerolactone (GVL) catalyzed by Lewis acid zeolites. Reaction kinetics studies show a first order dependence on ML and 2-butanol, confirm that the hydride shift is the rate-limiting step, and support a dual-binding mechanism on a single Lewis acid site. All catalysts generate GVL with selectivities >97\%, with Hf-Beta exhibiting the highest activity in the temperature range of 393 to $453 \mathrm{~K}$. Sn-, Zr-, and HfBeta show apparent activation energies of ca. $52 \mathrm{~kJ} \mathrm{~mol}^{-1}$, which is significantly lower than that of Ti-Beta $\left(69 \mathrm{~kJ} \mathrm{~mol}^{-1}\right)$. Secondary alcohols consistently exhibit higher reaction rates than primary alcohols with lower apparent activation energies. Increasing polarity of the hydrogen donor leads to a decrease in reaction rates. The experimental data is used to build a kinetic model for the MPV reaction in a tubular packed-bed reactor.
\end{abstract}

\title{
Keywords
}

Liquid-phase transfer hydrogenation; $\gamma$-valerolactone; Lewis acids; Zeolites; Reaction kinetics 


\section{Introduction}

Biomass conversion to sustainable chemicals and fuels requires the development of efficient catalytic processes capable of converting highly complex and oxygenated precursors to platform molecules. Ideally, selective deoxygenation and hydrogenation must occur under mild conditions while simultaneously minimizing unit operations. Transfer hydrogenations are versatile reactions that avoid the use of high pressures of molecular hydrogen by using molecules capable of donating hydrogen atoms in the liquid-phase [1-5]. In particular, the Meerwein-Ponndorf-Verley (MPV) reaction, wherein an alcohol donates a hydride to an aldehyde or ketone, has shown promising results in several biomass-relevant reaction schemes. Examples include the conversion of: crotonaldehyde to crotyl alcohol and butanal [6]; 5-(hydroxymethyl)furfural to 2,5bis(ethoxymethyl)furan [7]; levulinates to $\gamma$-valerolactone [8, 9]; and intramolecular hydride transfers in hexoses, pentoses, and other sugars [10-19].

Traditionally, homogenous Lewis acids catalyze the MPV reaction as shown for aluminum alkoxides $[20,21]$ in an isopropanol/ketone system, for lanthanide complexes in the reduction of aryl ketones [22], and more recently for actinide isopropoxides [23]. The reaction mechanism involves a cyclic six-membered transition state where the carbonyl and the alcohol are both coordinated to the same metal center. The reaction proceeds through a direct hydride shift where the hydrogen on the $\mathrm{C}-1$ position of the alcohol is directly transferred to the carbonyl carbon of the ketone/aldehyde. To overcome the problems associated with using homogenous catalysts, such as expensive separations and moisture sensitivity, many heterogeneous catalysts have been studied for the MPV reaction. These include metal oxides [24, 25], hydrotalcites [26, 27], and 
zeolites [28-32]. In particular, zeolites containing Lewis acid centers have shown very high activity and selectivity under mild reaction conditions [33-36]. Lewis acidic metal centers tetravalently incorporated into a silicate framework can coordinate with and polarize carbonyl functional groups [37, 38]. It is proposed that these metal centers coordinate the ketone and alcohol to form the same six-membered transition state as that formed with homogenous MPV catalysts. Various Lewis acid zeolites are capable of catalyzing the MPV reaction including Al-, Ti-, Sn-, and Zr-containing zeolites.

Recently, we reported on the one-pot conversion of xylose-derived furfural into $\gamma$ valerolactone (GVL) using the combined action of zeolites featuring Lewis and Brønsted acid sites [8]. GVL is a versatile platform molecule that has the functionality and reactivity to be upgraded to fuel additives, fuels, and commodity chemicals [39-43]. GVL is stable and non-toxic, and has shown promise as an effective solvent for sugar production by breaking down lignocellulosic biomass [44]. In our domino-like reaction sequence, furfural was reduced to furfuryl alcohol (FA) via an MPV reaction with 2butanol catalyzed by a Lewis acid; next, FA was converted to levulinic acid (LA) through a hydrolytic ring opening catalyzed by a Brønsted acid; finally, LA was reduced via a second MPV step to 4-hydroxypentanoate (4HP), which underwent a spontaneous lactonization to form GVL and water. GVL selectivity values always exceeded $94 \%$, but it was observed that Ti-, Sn-, and Zr-Beta catalysts featured drastically different turnover rates for the second MPV step, with Zr-Beta having the highest activity. Assary et al. showed with computational techniques that stronger Lewis acids better stabilize the sixmembered transition state for the rate-limiting hydride shift step [45]. Indeed, changing the identity of the framework heteroatom can alter the Lewis acid character of the zeolite; 
however, Lewis acidity is also highly dependent on the nature of the solvent and reacting molecules. A difficult challenge exists in correctly predicting which catalyst will be optimal for a specific substrate/solvent combination. For example, Boronat et al. showed that while Sn-Beta is more active for the reduction of cyclohexanone in 2-butanol, ZrBeta is more active for the reduction of benzaldehyde in 2-butanol under identical reaction conditions [46]. The nature of the hydrogen donor also had a dramatic impact on the reaction rates. As such, establishing a robust kinetic framework that describes the governing parameters of the ML to GVL transformation over a wide range of conditions is of great relevance to understand, and ultimately predict, the performance of Lewis acid zeolites in transfer hydrogenation reactions.

In this work, we present an experimental study aimed at extracting relevant kinetic parameters that describe the catalytic performance of Lewis acid catalysts during the reduction of ML to form GVL. We propose a set of elementary steps, derive a rate expression for the overall reaction, and perform reactivity measurements to confirm reaction orders and identify the rate-limiting step in the mechanism. We quantitatively compare the kinetic parameters of Ti-, Sn-, Zr-, and Hf-Beta catalysts over a wide range of temperatures and find that Hf-Beta has the highest activity of all catalysts. We also study the effect of varying the hydrogen donor by determining the kinetic parameters when using primary and secondary alcohols with varying carbon chain lengths. 


\section{Experimental methods}

\subsection{Catalyst synthesis}

Lewis acid zeolites with the Beta topology were synthesized in fluoride media following the procedure outlined by Corma et al.[47], using different heteroatom metal precursors. For example, Hf-Beta was prepared as follows: $27.16 \mathrm{~g}$ of tetraethylammonium hydroxide (Sigma-Aldrich, 35\% (w/w) in water) and $23.97 \mathrm{~g}$ of tetraethylorthosilicate (Sigma-Aldrich, $\geq 99 \%$ (w/w)) were added to an open Teflon jar. The mixture was magnetically stirred at room temperature for $90 \mathrm{~min}$. An additional 15 $\mathrm{ml}$ of deionized water was added and the mixture was cooled in an ice bath. Then, $0.37 \mathrm{~g}$ of hafnium(IV) chloride (Sigma-Aldrich, 98\% (w/w)) was dissolved in $2 \mathrm{ml}$ of ethanol, and this solution was added dropwise to the mixture while stirring on ice. The solution was left uncovered while stirring to complete the hydrolysis of TEOS, evaporate the ethanol, and reach approximately $2 \mathrm{~g}$ of water above the target water content. Then, 2.62 $\mathrm{g}$ of hydrofluoric acid (Sigma-Aldrich, $48 \%(\mathrm{w} / \mathrm{w})$ in water) was added dropwise and the mixture was homogenized using a PTFE spatula, resulting in a thick paste. Next, $0.36 \mathrm{~g}$ of previously-made Hf-Beta was sonicated in $2 \mathrm{ml}$ deionized water and added into the mixture as seeds. The mixture was homogenized and allowed to evaporate to a final weight of $33.96 \mathrm{~g}$. The final molar composition of the gel was $1 \mathrm{SiO}_{2} / 0.01 \mathrm{HfCl}_{4} / 0.56$ TEAOH / 0.56 HF / 7.5 $\mathrm{H}_{2} \mathrm{O}$. The thick paste was transferred to a Teflon-lined stainless steel autoclave and heated to $413 \mathrm{~K}$ in a static oven for $20-40$ days. The solids were recovered by filtration, washed extensively with water and ethanol, and dried at $373 \mathrm{~K}$ overnight. The solids were calcined at $923 \mathrm{~K}$ for $10 \mathrm{~h}$ with a $1 \mathrm{~K} / \mathrm{min}$ ramp and $1 \mathrm{~h}$ stops at $423 \mathrm{~K}$ and $623 \mathrm{~K}$ at a flow rate of $300 \mathrm{ml} \mathrm{min}^{-1}$ of dry air (Airgas, ultra zero grade) to 
remove the organic content in pores of the crystalline material. After calcination, the solid yield was $80-90 \%$. The other metal precursors used were: tin(II) chloride dihydrate (Sigma-Aldrich, 99.99\% (w/w)), zirconium(IV) oxychloride octahydrate (Sigma-Aldrich, 99.5\% (w/w)), and titanium(IV) isopropoxide (Sigma Aldrich, 99.999\% (w/w)). All the catalysts were synthesized to achieve a silicon/metal ratio of ca. 100 .

\subsection{Catalyst characterization}

The crystal structures of Beta zeolite catalysts were determined from powder Xray diffraction (PXRD) patterns collected using a Bruker D8 diffractometer using $\mathrm{Cu} \mathrm{K} \alpha$ radiation $(40 \mathrm{kV}, 40 \mathrm{~mA})$. Nitrogen adsorption and desorption isotherms were measured on a Quantachrome Autosorb iQ apparatus at liquid nitrogen temperature (77 K). Prior to the adsorption analysis, all samples were pelleted and degassed under vacuum for $12 \mathrm{~h}$ at $623 \mathrm{~K}$. Micropore $\mathrm{N}_{2}$ uptake was recorded at $\mathrm{P} / \mathrm{P}_{0}=0.01$, and total pore volume was recorded at $\mathrm{P} / \mathrm{P}_{0}=0.95$. Ultraviolet-visible (UV-vis) spectra were recorded using a Cary 5000 (Varian) instrument equipped with a Praying Mantis diffuse reflectance accessory (Harrick Scientific Products) on calcined samples using a barium sulfate blank. Reflectance measurements were converted to absorbance using the Kubelka-Munk function. Elemental analysis was performed with a CCD-based inductively coupled plasma (ICP) atomic emission spectrometer (Activa-S, HORIBA Scientific). Samples were dissolved in $48 \% \mathrm{HF}$ and diluted into $3 \% \mathrm{HNO}_{3}$ before analysis. A 5-point calibration curve was built using the following ICP standards: $1000 \mathrm{ppm} \mathrm{Zr}$ in $3 \% \mathrm{HNO}_{3}$ / trace $\mathrm{HF}, 1000$ ppm Sn in 10\% $\mathrm{HCl}, 1000$ ppm Ti in $2 \% \mathrm{HNO}_{3}$ / trace $\mathrm{HF}, 1000$ ppm Hf in $5 \% \mathrm{HNO}_{3}$ / trace $\mathrm{HF}$ (all TraceCERT®) on the following spectral lines: $327.305 \mathrm{~nm} \mathrm{Zr}$ line, 189.989 nm Sn line, 339.978 nm Hf line, $336.121 \mathrm{~nm}$ Ti line. 
Fourier transform infrared (FT-IR) spectra were collected with a Bruker Vertex 70 spectrophotometer equipped with an $\mathrm{Hg}-\mathrm{Cd}-\mathrm{Te}$ (MCT) detector. Each spectrum was recorded by averaging 128 scans at $2 \mathrm{~cm}^{-1}$ resolution in the $4000-400 \mathrm{~cm}^{-1}$ range. Zeolite Beta catalysts were pressed into self-supporting wafers $\left(8-10 \mathrm{mg} \mathrm{cm}^{-2}\right)$ that were sealed within a high temperature cell (Harrick Scientific) with ZnSe windows. Zeolite wafers were calcined in flowing air (Airgas, zero grade, $25 \mathrm{ml} \mathrm{min}^{-1}$ ) at $773 \mathrm{~K}$ for $8 \mathrm{~h}$, evacuated at $573 \mathrm{~K}$ for $3 \mathrm{~h}(<0.01 \mathrm{~Pa}$, dynamic vacuum, Edwards' T-Station 75 Turbopump), and cooled to $298 \mathrm{~K}$ in vacuum. A reference spectrum was acquired before dosing with excess $\mathrm{CD}_{3} \mathrm{CN}$ (Sigma Aldrich, 99.8\% (atom D)) vapor under static vacuum. Once dynamic vacuum was re-established, the difference spectrum was acquired.

\subsection{Kinetic studies of MPV reduction of levulinates}

Flow reactions were conducted in a $0.46 \mathrm{~cm}$ I.D. tubular stainless steel reactor mounted inside a $30 \mathrm{~cm}$ long aluminum block within an insulated single-zone furnace (Applied Test Systems Series 3210, $850 \mathrm{~W} / 115 \mathrm{~V}$ ). The catalyst was pelleted and sieved to obtain $75-150 \mu \mathrm{m}$ particles. The catalyst particles were then diluted into 5 times their weight in inert $\alpha$-aluminum oxide (Sigma Aldrich, >99\% (w/w)) with the same particle size range, creating a bed approximately $2.5 \mathrm{~cm}$ long. The bed was loaded between glass wool plugs and supported by additional $\alpha$-aluminum oxide. The reaction temperature was monitored by a K-type thermocouple (Omega, inconel) placed inside the bed and a PID temperature controller (Cole-Parmer, Digi-Sense Advanced Temperature Controller Series 89000). Prior to reaction, the packed bed was dried under flowing $\mathrm{N}_{2}$ gas (Airgas, grade 5, $300 \mathrm{ml} \mathrm{min}^{-1}$ ) at $423 \mathrm{~K}$ for $2 \mathrm{~h}$. Liquid-phase reactants were introduced with a Waters 515 HPLC pump and the entire system was pressurized under 15-20 bar of $\mathrm{N}_{2}$ 
using a backpressure regulator (Swagelok). The effluent was collected in a high pressure separator (Jerguson Gage and Valve Co., Series R20) at room temperature.

For sample quantification, a known amount of 1,3,5-tri-tert-butylbenzene (Sigma Aldrich, $97 \%(w / w))$ in the same solvent as the effluent, was added as an external standard. Liquid samples were analyzed by gas chromatography (Agilent $6890 \mathrm{~N}$ ) equipped with a methoxy-siloxane capillary column (HP-1, $30 \mathrm{~m} \times 0.25 \mathrm{~mm} \times 0.25 \mu \mathrm{m})$ connected to a flame ionization detector. All mass balances exceeded $97 \%$ for all experiments. The conversions are determined based on initial and final ML concentrations and the reaction rates are calculated based on GVL yield. In the runs where methyl levulinate is used as a solvent, the rates and conversions are based on the alcohol reactant. Conversion is defined as:

$$
\begin{aligned}
& X=1-\frac{C_{M L}}{C_{M L, 0}} \\
& X_{M L, \text { solvent }}=1-\frac{C_{X-O H}}{C_{X-O H, 0}}
\end{aligned}
$$

Yield is defined as:

$$
\begin{aligned}
& Y=\frac{C_{G V L}}{C_{M L, 0}} \\
& Y_{M L, \text { solvent }}=\frac{C_{X=O}}{C_{X-O H, 0}}
\end{aligned}
$$


Where $X$ is the conversion, $Y$ is the yield, $C_{i}$ is the molar concentration $\left(\mathrm{mol} \mathrm{dm}^{-3}\right)$ of species i recovered in a given reactor sample and $C_{i, 0}$ is the initial concentration of reactant fed at a constant volumetric flow rate.

Kinetic studies were conducted in a differential reactor bed in which levulinate conversion was controlled to be $<10 \%$. For some runs, a small amount of ethyl, propyl or butyl levulinate (XL) production was observed when using ML as the reactant, but total ML conversion was always kept below $10 \%$. The other levulinates undergo an identical reduction to ML and generate variants of $4 \mathrm{HP}$, which subsequently lactonize to GVL; consequently, they are treated as equivalent to $\mathrm{ML}$ in the overall reactant pool, and do not affect GVL selectivity negatively. Selectivity is defined as:

$$
S_{G V L}=\frac{C_{G V L}}{C_{M L, 0}-C_{M L}-C_{X L}}
$$

Volumetric flow rates for the activation energy studies and order studies ranged from 0.5 to $2.5 \mathrm{ml} \mathrm{min}^{-1}$ corresponding to space velocities ranging from 0.1 to $10^{3}$ (mol reactant $)(\mathrm{mol} \mathrm{metal} * \mathrm{~s})^{-1}$. The concentration of reactant was kept at $0.02 \mathrm{~mol} \mathrm{dm}^{-3}$ for activation energy studies and in the range of 0.0075 to $0.03 \mathrm{~mol} \mathrm{dm}^{-3}$ for reaction order studies. Activation energy experiments were performed in a temperature range of 393$453 \mathrm{~K}$, and all other studies were performed at $423 \mathrm{~K}$. Reactants and solvents used were: 2-butanol, 2-propanol, 1-butanol, 1-propanol (Sigma Aldrich, $\geq 99.5 \%$ (w/w) anhydrous);

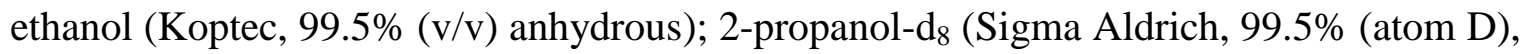
anhydrous); methyl levulinate (Sigma Aldrich, $\geq 98 \%$ (w/w)). Solvents were dried with activated $4 \AA$ molecular sieves (Sigma Aldrich, 4-8 mesh beads) prior to use. 


\section{Results and Discussion}

\subsection{Synthesis and characterization of Ti-, Sn-, Zr-, and Hf-containing Beta zeolites}

Characterization data of all Beta catalysts are given in Table 1. X-ray diffraction patterns (Fig. S1, Supporting Information) of Ti-, Sn-, Zr-, and Hf-Beta were consistent with the BEA topology. The asymmetry of the peak in the range of $2 \theta=7-9^{\circ}$ in the HfBeta and Zr-Beta powder patterns indicates an increase in the relative proportion of the polymorph B in the crystal structure, an effect previously reported for Zr-Beta by Zhu et $a l$.[32]. No peaks due to metal oxide or other crystalline impurities were detected. The micropore volumes of all catalysts, calculated from the nitrogen adsorption isotherms at 77 K (Fig. S3, Supporting Information), were consistent with the Beta topology measuring ca. $0.20 \mathrm{~cm}^{3} \mathrm{~g}^{-1}$ at $P / P_{0}=0.01$. The slight variations in total pore volume and external surface area indicate slight differences in crystal size and morphology between the samples. Elemental analysis by ICP-AES shows Si/M ratios in the range of 108-121, close to the theoretical value of 100 used in the synthesis gels. Synthesizing these zeolites in fluoride media has been shown to produce defect-free frameworks, which translate to pore structures with high hydrophobicity [10].

The presence of isolated Lewis acidic $\mathrm{M}^{4+}$ centers incorporated in the framework of the zeolites was demonstrated qualitatively by diffuse-reflectance UV-vis spectroscopy, which shows a single peak at $\sim 200 \mathrm{~nm}$ for each catalyst (Fig. S2, Supporting Information). The absence of peaks or shoulders in the $230-250 \mathrm{~nm}$ range indicates a lack of detectable $\mathrm{MO}_{\mathrm{x}}$ species. IR spectra of Ti- and Sn-Beta collected after saturation with $\mathrm{CD}_{3} \mathrm{CN}$ and subsequent evacuation at $298 \mathrm{~K}$ (Fig. S4, Supporting Information) shows 
bands at $\sim 2308-2316 \mathrm{~cm}^{-1}$ consistent with $\mathrm{C} \equiv \mathrm{N}$ stretching vibrations for $\mathrm{CD}_{3} \mathrm{CN}$ bound to Lewis acidic centers, and at $\sim 2276 \mathrm{~cm}^{-1}$ for $\mathrm{CD}_{3} \mathrm{CN}$ bound to silanol groups $[48,49]$. These spectra indicate the presence of Lewis acid centers as well as Brønsted acidic hydroxyl groups in the Beta catalysts.

\subsection{Proposed mechanism for MPV reaction over metal sites and reaction order studies}

The reduction of ML to 4HP and subsequent intramolecular lactonization over Hf-Beta in excess 2-butanol $(\mathrm{BuOH})$ at $423 \mathrm{~K}$ yields only one major product, GVL, for ML conversions ranging from 1 to $100 \%$. The intermediate $4 \mathrm{HP}$ could not be detected, which indicates that the intramolecular ring-closing is very fast at the reaction conditions investigated. Abdelrahman et al. showed that in the presence of Brønsted acidity and temperatures above $323 \mathrm{~K}$ lactonization rates are high, leading to high GVL selectivity and the absence of detectable 4HP intermediates [50]. A small amount of butyl levulinate (BL) is observed $(<5 \%)$, indicating a concurrent acid-catalyzed esterification of ML with $\mathrm{BuOH}$. This side reaction does not alter the reaction pathway since BL can be converted to GVL along the exact same mechanism as that for ML.

A proposed catalytic cycle for the MPV reaction of ML with 2-BuOH over a single catalytic center in Beta zeolite based on a set of elementary steps is shown in Scheme 1 . The catalytic cycle is consistent with previously proposed mechanisms for the MPV reaction [46]. The active Lewis acid site is hypothesized to be a partially hydrolyzed 'open site' where the metal is coordinated to three O-Si framework groups and one hydroxyl group [48]. The reaction proceeds in the following steps: adsorption and deprotonation of $\mathrm{BuOH}$ over the Lewis acid center (step 1); adsorption of ML (step 2) 
and hydride shift from deprotonated $\mathrm{BuOH}$ to ML through a six-membered cyclic transition state (step 3); desorption of 2-butanone ( $\mathrm{BuO}$ ) (step 4); and hydrogen transfer from the catalyst and desorption of 4HP (step 5). 4HP then undergoes a spontaneous intramolecular ring-closure and a Brønsted acid catalyzed release of methanol $(\mathrm{MeOH})$ to form GVL (step 6). Based on computational studies, the hydride shift is the slowest step in the mechanism and constitutes the rate-determining step. We further assume that all adsorption and desorption steps are in quasi-equilibrium, that all species in the reaction including small amounts of residual water $\left(\mathrm{H}_{2} \mathrm{O}\right)$ can act as singly-bound inhibitors, and that the intramolecular lactonization of 4HP is very fast and irreversible (Scheme A2, Appendix A). The fast lactonization step results in a product sink making the concentration of $4 \mathrm{HP}$ very small, and consequently, the reverse reaction of step 3 (i.e., 4HP back to ML) is negligible. A rate expression for the rate of GVL production normalized per catalytic site $\left(\mathrm{mol}\left(\mathrm{mol} \mathrm{metal}{ }^{*}\right)^{-1}\right)$ is given by Eq. 6 .

$$
r^{\prime}=\frac{k_{f, H} K_{M L^{*}} K_{B u O H} C_{M L} C_{B u O H}}{1+K_{M L} C_{M L}+K_{B u O H} C_{B u O H}+K_{G V L} C_{G V L}+K_{H_{2} O} C_{H_{2} O}+K_{4 H P} C_{4 H P}+K_{M e O H} C_{M e O H}+K_{B u O} C_{B u O}}
$$

In this equation, $C_{i}$ terms are liquid-phase concentrations $\left(\mathrm{mol} \mathrm{dm}^{-3}\right)$ for species $i$, and $K_{i}$ are the equilibrium constants $\left(\mathrm{dm}^{3} \mathrm{~mol}^{-1}\right)$ relating liquid-phase species to species that are singly bound to the Lewis sites (Scheme A2). $K_{M L^{*}}$ is the equilibrium constant relating free ML to ML bound specifically to sites that already have a bound $\mathrm{BuOH}$ molecule. $k_{f, H}$ is the forward rate constant $\left(\mathrm{s}^{-1}\right)$ for the hydride shift.

In excess of $\mathrm{BuOH}$, we can assume $\mathrm{BuOH}^{*}$ constitutes the majority of bound species on the acid sites. Therefore, the third term in the denominator dominates over the others, leading to the further simplified expression (Eq. 7), which shows first order 
dependence on ML concentration. The expression for the apparent rate constant is given in Eq. 8, and the expression for the apparent activation energy $\left(E_{a}\right)$ consisting of the activation energy of the hydride shift and the enthalpy of adsorption of ML onto an already occupied site, is given in Eq. 9 .

$$
\begin{aligned}
& r^{\prime}=\left(k_{f, H} K_{M L^{*}}\right) C_{M L} \\
& k_{a p p, B u O H}=k_{f, H} K_{M L^{*}} \\
& E_{a, a p p, B u O H}=E_{a, H}+\Delta H_{a d s, M L^{*}}
\end{aligned}
$$

Conversely, in excess ML, we can assume ML* constitutes the majority of bound species on the acid sites. Therefore, the second term in the denominator dominates over the others, leading to the further simplified expression (Eq. 10), which shows first order dependence on $\mathrm{BuOH}$ concentration. If we assume that $K_{M L}$ is approximately equal to $K_{M L^{*}}$, then the apparent rate constant in excess ML is simplified to Eq. 11. This gives an expression for the apparent $\mathrm{E}_{\mathrm{a}}$ (Eq. 12), which consists of the activation energy of the hydride shift and the enthalpy of adsorption of 2-BuOH onto an unoccupied site.

$$
\begin{aligned}
& r^{\prime}=\left(\frac{k_{f, H} K_{M L^{*}} K_{\text {ВиOH }}}{K_{M L}}\right) C_{\text {ВиOH }} \\
& k_{a p p, M L}=k_{f, H} K_{\text {BuOH }} \\
& E_{a, a p p, M L}=E_{a, H}+\Delta H_{a d s, B u O H}
\end{aligned}
$$

The initial turnover frequencies were measured in terms of GVL production normalized by total metal content of zeolite, at an ML conversion $<10 \%$. As shown in Fig. 
1, first order dependencies of initial rates to ML concentration in solvent excess of $\mathrm{BuOH}$ and of $\mathrm{BuOH}$ concentration in solvent excess of $\mathrm{ML}$ are confirmed by slope values of the $\log$ rate vs. $\log$ initial concentration plots that approach unity. These first order dependencies support our proposed mechanism where both reactant molecules are coordinated to a single catalytic center. These data are in agreement with several computational studies on the MPV reaction over Beta zeolites using density functional theory $[45,46]$, as well as the established mechanism for MPV reaction on Al(III) isopropoxide [20].

\subsection{Exclusion of mass transport limitations and confirmation of rate-determining step}

Measured initial rates would also show an apparent first-order dependence on ML or $\mathrm{BuOH}$ concentration for a process limited by the diffusion of reactants to active sites located within the zeolite pores. To rule out intercrystalline heat and mass transport artifacts, the linear velocity in the reactor was varied while maintaining a constant space velocity at temperatures of 393, 423, and $453 \mathrm{~K}$. As shown in Fig. S5, the rate of GVL production remains constant (within experimental error) for all linear velocities at the full range of temperatures, indicating that no external mass transfer limitations exist at these conditions. Next, to ensure the absence of intracrystalline heat and mass transport artifacts, turn over frequencies for $\mathrm{Hf}-\mathrm{Beta}$ zeolites with varying $\mathrm{Si} / \mathrm{M}$ ratios were measured and compared. Initial rates were determined for Hf-Beta200 (Si/Hf ratio of 190, as confirmed by ICP-AES elemental analysis) and Hf-Beta300 (Si/Hf ratio of 336) under identical kinetic reaction conditions to those used for the original Hf-Beta catalyst at 393, 423, and 453 K. As shown in Fig. S6, the rates normalized per total metal site are constant for all temperatures tested, thus confirming that the reaction conditions used in 
this study satisfy the Koros-Nowak criterion and do not exhibit internal heat or mass transport limitations. All kinetic data were collected in the absence of significant catalyst deactivation, as confirmed by replicating initial runs in a series and obtaining identical activity values.

To support our hypothesis that the rate-limiting step of the reaction is the hydride shift, we measured the kinetic isotope effect (KIE) using 2-propanol- $\mathrm{H}_{8}$ and 2-propanol$\mathrm{D}_{8}$ as the solvent. The $\mathrm{k}_{\mathrm{app}, \mathrm{H}} / \mathrm{k}_{\mathrm{app}, \mathrm{D}}$ ratio at $423 \mathrm{~K}$ was $2.01 \pm 0.33$ (Table $\mathrm{S} 1$, Supporting Information). This KIE value indicates that the elementary steps for adsorption and deprotonation do not limit rates of ML hydrogenation prior to the kinetically relevant hydride shift. Incorporation of the deuteron in the C-4 position in the GVL product was confirmed by ${ }^{1} \mathrm{H}$ NMR (Fig. S7, Supporting Information). The same effect can be seen when performing the experiment in excess ML where the $\mathrm{k}_{\mathrm{app}, \mathrm{H}} / \mathrm{k}_{\mathrm{app}, \mathrm{D}}$ ratio at $423 \mathrm{~K}$ was $1.90 \pm 0.10$ (Table S1, Supporting Information). Previous studies on the MPV reduction catalyzed by homogenous aluminum(III) complexes have yielded experimental KIE values of 2.3 and $3.0[20,51]$. The exact nature of the vibrational mode of the bimolecular six-membered transition state is difficult to determine for heterogeneous catalytic sites even with density functional theory (DFT) given the need to use tight convergences for the force constants and appropriate dispersive interactions to locate the transition states. At the given temperatures, assuming the transition state oscillation is a combination of C-H bond scissoring $\left(\sim 1400 \mathrm{~cm}^{-1}\right)$ and $\mathrm{C}-\mathrm{H}$ bond stretching $\left(\sim 2900 \mathrm{~cm}^{-1}\right)$, a theoretical KIE value between 1.9-3.6 is expected (see derivation in section A, Supporting Information). Given the absence of mass transfer limitations, our 
experimental KIE values imply that the bending vibrational mode is dominant in the transition state, possibly due to confinement in the narrow zeolite pores.

\subsection{Temperature effects}

Having established reaction orders and ruled out heat and mass transfer limitations, the apparent rate constant $\mathrm{k}_{\mathrm{app}}$ and Arrhenius parameters were explicitly determined under differential reaction conditions in a temperature range of 393-453 K (Table 2). The apparent activation energy for the reaction over Hf-Beta catalyst in excess of $\mathrm{BuOH}$ is $52.5 \pm 1.9 \mathrm{~kJ} \mathrm{~mol}^{-1}$ and the pre-exponential factor is $4.1 \times 10^{6}\left(\mathrm{~mol} \mathrm{dm}^{3}\right)(\mathrm{mol}$ metal*s*mol ML) ${ }^{-1}$. This apparent activation energy agrees well with that found for levulinic acid hydrogenation in liquid water using Ru-based catalysts (48 $\mathrm{kJ} \mathrm{mol}^{-1}$ ) [50]. In addition, the experimental value matches closely with the apparent activation energy of $53.9 \mathrm{~kJ} \mathrm{~mol}^{-1}$ calculated by Assary et al. for ethyl levulinate in isopropanol solvent over Zr-Beta catalyst [45]. We would expect $\mathrm{Hf}$ and $\mathrm{Zr}$ sites to behave very similarly due to their comparable electronic properties and atomic sizes. The activation energy for the reaction over Hf-Beta catalyst in excess ML is $44.8 \pm 1.4 \mathrm{~kJ} \mathrm{~mol}^{-1}$ and the pre-exponential factor is $3.8 \times 10^{4}\left(\mathrm{~mol} \mathrm{dm}^{3}\right)\left(\mathrm{mol} \mathrm{metal}{ }^{*} \mathrm{~s}^{*} \mathrm{~mol} \mathrm{BuOH}\right)^{-1}$. The decrease in apparent activation energy is attributed to the stronger adsorption of ML on the metal site compared to the adsorption of $\mathrm{BuOH}$ on the metal site based on the simplified rate expressions (Eq. 7 and 10). This trend agrees with the theoretical difference in adsorption enthalpies of ML and BuOH of $14.2 \mathrm{~kJ} \mathrm{~mol}^{-1}$ calculated by Assary et al. [45]. In addition, the two order of magnitude difference in the pre-exponential factors when switching solvents leads to a large difference in the free energies of adsorption, which is reflected by an order of magnitude decrease in the apparent rate constant at $423 \mathrm{~K}$. More 
specifically, $\mathrm{k}_{\text {app }}$ is $0.110\left(\mathrm{~mol} \mathrm{dm}^{3}\right)\left(\mathrm{mol} \mathrm{metal}{ }^{*} \mathrm{~s}^{*} \mathrm{~mol} \mathrm{BuOH}\right)^{-1}$ when operating in excess ML compared to $1.33\left(\mathrm{~mol} \mathrm{dm}^{3}\right)\left(\mathrm{mol} \mathrm{metal}^{*} \mathrm{~s} * \mathrm{~mol} \mathrm{ML}\right)^{-1}$ when operating in excess $\mathrm{BuOH}$.

\subsection{Comparison of Ti, Sn, Zr, Hf-Beta catalysts}

The MPV reduction of ML has previously been shown to occur with high activity and selectivity over Sn- and Zr-Beta catalysts in batch reactions. Although previous studies in liquid-phase batch reactors report very low conversions for Ti-Beta $(\sim 1 \%)$, we now quantitate its turnover rate for the MPV reaction [8]. Our results show that Hf-Beta converts ML to GVL in $\mathrm{BuOH}$ with high selectivity and with a rate constant $(1.33$ (mol $\left.\mathrm{dm}^{3}\right)\left(\right.$ mol metal*s*mol ML) $\left.{ }^{-1}\right)$ that is twice as large than that of $\mathrm{Zr}$-Beta $(0.684$ (mol $\left.\left.\mathrm{dm}^{3}\right)(\text { mol metal*s*mol ML) })^{-1}\right)$, and seven times larger than that of Sn-Beta $(0.192(\mathrm{~mol}$ $\left.\mathrm{dm}^{3}\right)\left(\right.$ mol metal*s*mol ML) $\left.{ }^{-1}\right)$ at $423 \mathrm{~K}$ (Table 2$)$. The marked differences in initial rates between the catalysts that arise in spite of the similar apparent activation energy values of $52.5 \pm 1.9,51.8 \pm 1.0$, and $51.7 \pm 2.1 \mathrm{~kJ} \mathrm{~mol}^{-1}$ for Hf-, Zr-, and Sn-Beta, respectively (Table 2), highlight the need to find the optimal Lewis acid catalyst for each reaction system. The activation energies and activities depend on the Lewis acidity of the sites in the specific reaction-solvent system. Due to the similar apparent activation energies in these zeolites, commensurate differences in activity were observed throughout the experimental temperature range (Fig. 2). However, for Ti-Beta, an apparent activation energy of 69.0 $\pm 2.2 \mathrm{~kJ} \mathrm{~mol}^{-1}$ was calculated, which translates to a rate constant that is three orders of magnitude smaller than that of Hf-Beta at $423 \mathrm{~K}$. 
The apparent activation energy consists of the sum of the activation energy of the hydride shift and the enthalpy of adsorption of ML onto a site already occupied by a bound $\mathrm{BuOH}$ molecule (Eq. 9). Our results indicate that the $\mathrm{E}_{\mathrm{a}}$ of the hydride shift and the adsorption enthalpy of ML are either very similar for Sn-, Zr-, and Hf-Beta, or that the differences in $E_{a}$ and adsorption enthalpies for each catalyst exactly offset to give the same apparent energies. We would expect Zr- and Hf-Beta to have similar $\mathrm{E}_{\mathrm{a}}$ and adsorption values since $\mathrm{Hf}$ and $\mathrm{Zr}$ have a similar size and electronic structure (s-d valence orbitals). However, it is surprising that Sn-Beta features similar apparent activation energy values, since Sn has a significantly smaller atomic radius and s-p valence electron orbitals. Evidently, the barriers for the hydrogen shift depend on the electronics of the entire reaction site, not just the metal atom alone. The $\mathrm{E}_{\mathrm{a}, \mathrm{H}}$ comprises numerous energetic contributions involving the heteroatom and its effect on the solvent, reactants and transition state, including: site geometry, charge transfer, and polarizability. In addition, it is unknown whether the adjacent hydroxyl group of the open site plays a role in transition state stabilization. Therefore, different energetic contributions could offset to give the same total apparent activation energy. Recently, Li et al. highlighted this balancing effect with an extended QM/MM model of heteroatom-containing zeolites for glucose-fructose isomerization [52]. It was reported that although the metal centers and the adjacent hydroxyl groups in Sn- and Zr-Beta have drastically different polarizabilities and Brønsted basicities, respectively, their contribution summed to almost the same apparent activation energy.

Pre-exponential factors for Hf-, Zr-, Sn-, and Ti-Beta are all within an order of magnitude, but they reflect the difference in relative reaction rates observed across the 
experimental temperature range (Table 2). Although the differences in the experimental pre-exponential factors are not statistically significant to $90 \%$ confidence (Table S2, Supporting Information), we expect to see differences in the free energy of binding and reaction depending on the identity of the heteroatom. Changes in site geometry or energetics likely restrict available conformations of bound intermediates and the transition state. In addition, varying binding strengths may contribute to differences in vibrational frequencies of bound species. These differences in free energy may stabilize the transition from reactants to the six-membered ring transition state for certain heteroatoms, leading to the observed differences in reaction rate.

The observed differences in initial rates that exist for catalysts possessing similar activation barriers could also be a result of different proportions of catalytically active sites with respect to total metal content. Previous studies of Ti- and Sn-Beta showed that the distribution of open sites was highly dependent on catalyst pretreatment such as calcination conditions, as well as initial exposure to the reaction environment $[46,53]$. The metal centers may interconvert between open and closed sites at reaction conditions. Different metal centers may have different M-O-Si hydrolysis rates, which would lead to different distributions of open and closed sites between the metals. At this time we cannot deconvolute these effects in our experimental data. The ability to quantitatively compare experimental kinetic parameters will facilitate the search for which fundamental physical properties are most important in predicting catalyst activity.

\subsection{Comparison of hydrogen donor properties}


We studied the effect of varying the position of the hydroxyl group and the carbon chain length of the hydrogen donor. Lewis acidity is highly dependent on the solvent environment, so it is important to study how solvent-catalyst systems may be optimized for higher activity $[54,55]$. The activation energies, pre-exponential factors, and rate constants at $423 \mathrm{~K}$ for the MPV reduction of ML over Hf-Beta are shown in Table 3. We found the most dramatic effect on the reaction rates was achieved by switching from a secondary to a primary alcohol donor (Fig. 3). BuOH, 2-propanol (2-PrOH), and cyclopentanol $(\mathrm{Cy}-\mathrm{PeOH})$ have activation energies of 52.5 $\pm 1.9,46.3 \pm 2.7$, and $56.9 \pm 2.2$ $\mathrm{kJ} \mathrm{mol}^{-1}$, respectively; whereas 1-butanol (1-BuOH), 1-propanol (1-PrOH), and ethanol (EtOH) have activation energies of $73.5 \pm 4.4,69.2 \pm 2.9$, and $70.2 \pm 4.2 \mathrm{~kJ} \mathrm{~mol}^{-1}$, respectively. We hypothesize that the lower apparent activation barrier is primarily due to the stabilization of the hydride shift transition state by the electron-donating alpha terminal methyl group in secondary alcohols, which leads to a lower $\mathrm{E}_{\mathrm{a}, \mathrm{H}}$. This can be quantitatively represented by the oxidation enthalpies of the respective alcohols, which clearly segregate between the primary and secondary alcohols (Table S3, Supporting Information). The pre-exponential factors for the reactions with primary alcohols are nearly two orders of magnitude greater than those for the secondary alcohols; a statistically significant result at $90 \%$ confidence (Table S2, Supporting Information). The absence of the alpha terminal methyl group likely reduces steric hindrance on both the bound intermediates and the transition state. Also, primary alcohols have access to a second C-1 hydrogen that can be transferred to ML during the six-membered ring transition state. This contributes both conformational and rotational degrees of freedom to the free energy along the reaction pathway. However, the larger pre-exponential factors 
of primary alcohols do not compensate for their unfavorable activation energies at the temperatures investigated; the reaction rate constants for primary alcohols are an order of magnitude lower than their secondary counterparts at $423 \mathrm{~K}$ (Table 3 ). The higher rates for secondary alcohols has been previously reported for transfer hydrogenations using primary and secondary alcohols over supported ruthenium catalysts [56].

Longer alcohol chains increase reaction rates relative to shorter chains. This effect is observed primarily in the pre-exponential factors, as the activation energies are nearly the same within the primary and secondary alcohol groups. The pre-exponential factor of 2-PrOH is an order of magnitude lower than that of $\mathrm{BuOH}$, and a similar decrease is seen when switching from 1-BuOH to 1-PrOH. In contrast, there is only a three-fold decrease in pre-exponential factor when switching from 1-PrOH to EtOH. The polarity of the alcohol, quantitatively represented by its dielectric constant, increases with decreasing chain length for the non-cyclic alcohols (Table S3, Supplemental Information). Cy-PeOH has a dielectric constant that lies in-between that of $\mathrm{BuOH}$ and 2-PrOH, and we see the same trend in the pre-exponential factors. An increase in solvent polarity most likely results in tighter binding to the Lewis acid center, and therefore, a decrease in flexibility of the bound intermediate and transition state. The importance of binding flexibility is evident in the large decrease in apparent rate constant, from 1.33 to $0.196\left(\mathrm{~mol} \mathrm{dm}^{3}\right)(\mathrm{mol}$ metal*s*mol ML) ${ }^{-1}$, when using $\mathrm{Cy}-\mathrm{PeOH}$ instead of $\mathrm{BuOH}$. The rigid structure of cyclopentanol limits the number of accessible conformations leading to a higher penalty for binding. The differences in solvent polarity may also lead to different partitioning in the hydrophobic zeolite pores and affect the strength of solvation of ML [57-60]. We note that the sizes of all studied alcohols are smaller than the size of a Beta zeolite pore [30]. 
Therefore, this work captures the trends of solvents that should be largely unaffected by constriction due to the pore size. It is important to determine how catalyst activity is affected by small changes in substrate geometry in order to increase the flexibility of catalytic processes to adapt to varying feedstocks.

\subsection{Kinetic model of packed-bed reactor}

An ideal packed-bed reactor kinetic model was developed to quantitatively describe the reduction of $\mathrm{ML}$ in $\mathrm{BuOH}$ over an $\mathrm{Hf}-\mathrm{Beta}$ catalyst. The reactor was assumed to operate under isothermal and constant pressure condition, with no radial gradients in concentration, temperature, or reaction rate. For the derivation, we used the simplified rate expression (Eq. 13), which has first-order dependence on ML

concentration $\left(\mathrm{mol} \mathrm{dm}{ }^{-3}\right)$ and the temperature dependent apparent rate constant $k_{\text {app }}((\mathrm{mol}$ $\left.\mathrm{GVL}^{*} \mathrm{dm}^{3}\right)\left(\mathrm{mol}\right.$ metal*s*mol ML) $\left.{ }^{-1}\right)$. This apparent rate constant can be calculated from the Arrhenius parameters (Eq. 14) determined from initial rate experiments listed in Table 2 and Table 3.

$r^{\prime}=k_{a p p} C_{M L}$

$k_{a p p}=A_{a p p} \exp \left(\frac{E_{a, a p p}}{R T}\right)$

The concentration profile for a packed-bed-reactor is given in Eq. 15. The detailed derivation for this equation is shown in section $\mathrm{C}$ of the Supporting Information.

$$
X=1-\exp \left(\frac{C_{M L, 0} k_{a p p}}{S V}\right)
$$


$X$ is the conversion in terms of GVL production, $S V$ is the space velocity $\left(\mathrm{mol} \mathrm{ML}_{0}\right)(\mathrm{mol}$ metal $\left.^{*}\right)^{-1}$, and $C_{M L, O}$ is the initial concentration of ML.

Fig. 4 shows the experimental values superimposed over the concentration profiles predicted by the model at space velocities in a range of 10-300 $\left(\mathrm{mol} \mathrm{ML}_{0}\right)(\mathrm{mol}$ metal $\left.{ }^{*}\right)^{-1}$ and conversions ranging from 10 to $80 \%$. There exists good agreement between the experimental and theoretical values obtained with the activation energies and pre-exponential factors calculated in previous sections. As such, we can model the behavior of the ML to GVL reaction using each of the different hydrogen-donating solvents as well as each of the different Beta catalysts with high fidelity. 


\section{Conclusions}

Hf-Beta was determined to be a highly active and selective catalyst for the MPV reduction of ML to 4HP and subsequent ring closing to GVL in 2-butanol. The reaction was confirmed to be first order in ML in 2-butanol solvent, and first order in 2-butanol in ML solvent. This supports a dual binding mechanism where the ketone and alcohol interact with a single metal site forming a six-membered transition state. The absence of intercrystalline and intracrystalline mass and heat transport limitations was confirmed by varying linear velocities and varying Beta zeolite metal content. A KIE value of ca. 2 corroborated that the rate-determining step is in fact the hydride shift, and that the transition state is dominated by bending rather than stretching vibrational modes. The apparent activation energy of the reaction over Hf-Beta was $52.5 \mathrm{~kJ} \mathrm{~mol}^{-1}$, which is similar to activation energies for LA hydrogenation and computational studies. We found that Hf-Beta was the most active out of Ti-, Sn-, and Zr-Beta catalysts. Sn-, Zr-, and HfBeta all had very similar activation energies, while that of Ti-Beta was higher at $69.0 \mathrm{~kJ}$ $\mathrm{mol}^{-1}$. A study of varying the hydrogen donor properties showed that secondary alcohols are much more active than primary alcohols with activation energies that are ca. $20 \mathrm{~kJ}$ $\mathrm{mol}^{-1}$ lower, most likely due to transition state stabilization of the $\mathrm{C}-1$ position during the hydride shift. In addition, decreasing chain length of the alcohol did not have an effect on the activation energies but did decrease the pre-exponential factors leading to three- to ten-fold decreases in rates in the experimental temperature range. We developed a kinetic model using the experimentally determined activation energies and pre-exponential factors to accurately predict conversions in a packed-bed reactor. 
This study provides the first quantification of kinetic parameters for the MPV reduction of liquid-phase substrates on zeolite Lewis acid catalysts. In addition, we provide a fully quantitative comparison of Ti-, Sn-, Zr-, and Hf-Beta initial rate constants, apparent activation energies, and pre-exponential factors for the reduction of ML in 2butanol. Experimentally quantifying the effects of varying Lewis acid metal centers and substrates is crucial for the design of effective heterogeneous catalysts for applications in biomass conversion.

\section{Acknowledgements}

The authors acknowledge financial support for this work from the U.S.

Department of Energy, Office of Science, Office of Basic Energy Sciences, Chemical

Sciences, Geosciences and Biosciences Division under grant no. DE-FG02-12ER16352 .

We also thank Marco B. Wonink and Anthony Crisci (Massachusetts Institute of Technology, Chemical Engineering) for their support in building the infrared spectroscopy in situ dosing system. 


\section{Appendix A. Abridged derivation of ML MPV turnover rate expression}

Here we show an abridged derivation of the rate expression for GVL production (Eq. 6) from the MPV reduction of ML with 2-butanol $(\mathrm{BuOH})$ as the hydrogen donor. The sequence of elementary steps is shown in Scheme A2. A complete derivation is given in section B in the Supporting Information. The kinetically relevant step is the hydride shift (step 3) based on the observed H/D KIE of $~ 2$ at $423 \mathrm{~K}$ on Hf-Beta when using 2-propanol- $\mathrm{D}_{8}$ reactant (Section 3.3). All the adsorption and desorption steps are assumed to be quasi-equilibrated, including steps 7-11, which allow species to bind and inhibit active sites. These steps are depicted as single adsorption and desorption steps even though they may represent a combination of elementary steps, such as deprotonation to form alkoxides. We also assume that the intramolecular ring-closing (step 6) is very fast and essentially irreversible. This assumption is reasonable given the reaction conditions at $423 \mathrm{~K}$, the presence of Brønsted acidity in the zeolite catalyst, and no detectable 4HP when analyzing reaction solutions. The rate expression for the ratedetermining step is $\left(\mathrm{mol} \mathrm{dm} \mathrm{d}^{-3} \mathrm{~s}^{-1}\right)$ :

$r_{r d s}=k_{f, H} C_{B u O H-M L^{*}}-k_{r, H} C_{B u O-4 H P^{*}}$

Where $C_{i}$ are the concentration of species $\left.i(\mathrm{~mol} \mathrm{dm})^{-3}\right)$, and $k_{i}\left(\mathrm{~s}^{-1}\right)$ are the forward and reverse rate constants for the hydride shift. The quasi-equilibrium assumption gives us the following expressions in terms of the adsorption/desorption equilibrium constant $K=\frac{k_{a d s}}{k_{d e s}}\left(\mathrm{dm}^{3} \mathrm{~mol}^{-1}\right)$ for each species. We show only the expression for steps 1 and 2. 


$$
\begin{gathered}
K_{\mathrm{BuOH}}=\frac{C_{\mathrm{BuOH}^{*}}}{C_{\mathrm{BuOH}} C_{*}} \\
K_{M L^{*}}=\frac{C_{B u O H-M L^{*}}}{C_{B u O H^{*}} C_{M L}}
\end{gathered}
$$

We assume pseudo-steady-state on the concentration of 4HP intermediate, and that the rate constant for lactonization $\left(k_{f, L}\right)$, is extremely large. After rearranging, we find the concentration of $4 \mathrm{HP}$ to be close to 0 , which is supported by GC analysis of reaction solutions. This means the concentration of bound intermediate 4HP species is also close to 0 . This allows us to simplify Eq. A1 to only the forward reaction. Replacing bound intermediates with solution phase species using the equilibrium Eq. (A2, A3), we obtain a rate expression in terms of free active sites.

$$
r_{r d s}=k_{f, H} K_{M L^{*}} K_{B u O H} C_{M L} C_{B u O H} C_{*}
$$

Combining the Lewis acid total site balance with the equilibrium constant expressions and rearranging allows us to isolate $C *$.

$$
C_{* t o t}=C_{*}\left(1+K_{M L} C_{M L}+K_{B u O H} C_{B u O H}+K_{G V L} C_{G V L}+K_{H_{2} O} C_{H_{2} O}+K_{4 H P} C_{4 H P}+K_{M e O H} C_{M e O H}+K_{B u O} C_{B u O}\right)
$$

Substituting the expression for $C *$ into A4 gives us:

$$
r_{r d s}=\frac{k_{f, H} K_{M L^{*}} K_{B u O H} C_{M L} C_{B u O H} C_{t o t *}}{1+K_{M L} C_{M L}+K_{B u O H} C_{B u O H}+K_{G V L} C_{G V L}+K_{\mathrm{H}_{2} O} C_{\mathrm{H}_{2} \mathrm{O}}+K_{4 H P} C_{4 H P}+K_{M e O H} C_{M e O H}+K_{B u O} C_{B u O}}
$$

If we normalize the rate by the concentration of total acid sites, which is assumed to be the metal content in the zeolite, we get the expression: 


$$
r^{\prime}=\frac{k_{f, H} K_{M L^{*}} K_{B u O H} C_{M L} C_{B u O H}}{1+K_{M L} C_{M L}+K_{B u O H} C_{B u O H}+K_{G V L} C_{G V L}+K_{H_{2} O} C_{H_{2} O}+K_{4 H P} C_{4 H P}+K_{M e O H} C_{M e O H}+K_{B u O} C_{B u O}}
$$

This rate has units of ( $\left.\mathrm{mol}(\mathrm{mol} \mathrm{metal})^{-1} \mathrm{~s}^{-1}\right)$. Further simplifications of this rate expression when using a large excess of either $\mathrm{BuOH}$ or ML are given in Section 3.2 Eq. 7-12. 


\section{References}

[1] M.J. Climent, A. Corma, S. Iborra, Green Chem., 16 (2014) 516.

[2] M. Dusselier, M. Mascal, B.F. Sels, Top Chemical Opportunities from Carbohydrate Biomass: A Chemist's View of the Biorefinery, in: Top. Curr. Chem., Springer Berlin Heidelberg, 2014, pp. 1-40.

[3] C. Aellig, F. Jenny, D. Scholz, P. Wolf, I. Giovinazzo, F. Kollhoff, I. Hermans, Catal. Sci. Technol., 4 (2014) 2326-2331.

[4] S. Van de Vyver, J. Geboers, P.A. Jacobs, B.F. Sels, ChemCatChem, 3 (2011) 82-94.

[5] M.J. Climent, A. Corma, S. Iborra, M.J. Sabater, ACS Catal., 4 (2014) 870-891.

[6] V.L. Sushkevich, I.I. Ivanova, S. Tolborg, E. Taarning, J. Catal., 316 (2014) 121-129.

[7] J.D. Lewis, S. Van de Vyver, A.J. Crisci, W.R. Gunther, V.K. Michaelis, R.G. Griffin, Y. RománLeshkov, ChemSusChem, 7 (2014) 2255-2265.

[8] L. Bui, H. Luo, W.R. Gunther, Y. Roman-Leshkov, Angew. Chem. Int. Ed. Engl., 52 (2013) $8022-$ 8025.

[9] M. Chia, J.A. Dumesic, Chem Commun (Camb), 47 (2011) 12233-12235.

[10] R. Gounder, M.E. Davis, J. Catal., 308 (2013) 176-188.

[11] H.J. Cho, P. Dornath, W. Fan, ACS Catal., 4 (2014) 2029-2037.

[12] M. Moliner, Y. Roman-Leshkov, M.E. Davis, Proc. Natl. Acad. Sci. U. S. A., 107 (2010) 61646168.

[13] R. Gounder, M.E. Davis, ACS Catal., 3 (2013) 1469-1476.

[14] Y. Román-Leshkov, M. Moliner, J.A. Labinger, M.E. Davis, Angew. Chem. Int. Ed., 49 (2010) 8954-8957.

[15] W.R. Gunther, Y. Wang, Y. Ji, V.K. Michaelis, S.T. Hunt, R.G. Griffin, Y. Román-Leshkov, Nat. Commun., 3 (2012) 1109.

[16] W.R. Gunther, Q. Duong, Y. Román-Leshkov, J. Mol. Catal. A: Chem., 379 (2013) 294-302.

[17] P.P. Pescarmona, K.P. Janssen, C. Delaet, C. Stroobants, K. Houthoofd, A. Philippaerts, C. De Jonghe, J.S. Paul, P.A. Jacobs, B.F. Sels, Green Chem., 12 (2010) 1083-1089.

[18] E. Taarning, S. Saravanamurugan, M. Spangsberg Holm, J. Xiong, R.M. West, C.H.

Christensen, ChemSusChem, 2 (2009) 625-627.

[19] C.M. Lew, N. Rajabbeigi, M. Tsapatsis, Microporous Mesoporous Mater., 153 (2012) 55-58.

[20] R. Cohen, C.R. Graves, S.T. Nguyen, J.M. Martin, M.A. Ratner, J. Am. Chem. Soc., 126 (2004) 14796-14803.

[21] E.J. Campbell, H. Zhou, S.T. Nguyen, Org. Lett., 3 (2001) 2391-2393.

[22] D.A. Evans, S.G. Nelson, M.R. Gagne, A.R. Muci, J. Am. Chem. Soc., 115 (1993) 9800-9801.

[23] B.P. Warner, J.A. D'Alessio, A.N. Morgan III, C.J. Burns, A.R. Schake, J.G. Watkin, Inorg. Chim. Acta, 309 (2000) 45-48.

[24] V. Ivanov, J. Bachelier, F. Audry, J. Lavalley, J. Mol. Catal., 91 (1994) 45-59.

[25] M.a.A. Aramendía, V. Borau, C. Jiménez, J.M. Marinas, J.R. Ruiz, F.J. Urbano, Appl. Catal., A, 244 (2003) 207-215.

[26] P. S. Kumbhar, J. Sanchez-Valente, J. Lopez, F. Figueras, Chem. Commun., (1998) 535-536.

[27] C. Jiménez-Sanchidrián, J.R. Ruiz, Appl. Catal., A, 469 (2014) 367-372.

[28] E. Creyghton, S. Ganeshie, R. Downing, H. Van Bekkum, J. Mol. Catal. A: Chem., 115 (1997) 457-472.

[29] J.C. van der Waal, K. Tan, H. van Bekkum, Catal. Lett., 41 (1996) 63-67.

[30] A. Corma, M.E. Domine, S. Valencia, J. Catal., 215 (2003) 294-304. 
[31] A. Corma, M.E. Domine, L. Nemeth, S. Valencia, J. Am. Chem. Soc., 124 (2002) 3194-3195.

[32] Y. Zhu, G. Chuah, S. Jaenicke, J. Catal., 227 (2004) 1-10.

[33] M. Moliner, Dalton Trans., 43 (2014) 4197-4208.

[34] M. Dusselier, P. Van Wouwe, S. De Smet, R. De Clercq, L. Verbelen, P. Van Puyvelde, F.E. Du Prez, B.F. Sels, ACS Catal., 3 (2013) 1786-1800.

[35] H.Y. Luo, L. Bui, W.R. Gunther, E. Min, Y. Román-Leshkov, ACS Catal., 2 (2012) 2695-2699.

[36] J.J. Pacheco, M.E. Davis, Proc. Natl. Acad. Sci. U. S. A., 111 (2014) 8363-8367.

[37] W.R. Gunther, V.K. Michaelis, M.A. Caporini, R.G. Griffin, Y. Román-Leshkov, J. Am. Chem. Soc., 136 (2014) 6219-6222.

[38] Y. Román-Leshkov, M.E. Davis, ACS Catal., 1 (2011) 1566-1580.

[39] I.T. Horváth, H. Mehdi, V. Fábos, L. Boda, L.T. Mika, Green Chem., 10 (2008) 238.

[40] J.Q. Bond, D.M. Alonso, D. Wang, R.M. West, J.A. Dumesic, Science, 327 (2010) 1110-1114.

[41] L. Qi, I.T. Horváth, ACS Catal., 2 (2012) 2247-2249.

[42] D.M. Alonso, S.G. Wettstein, J.A. Dumesic, Green Chem., 15 (2013) 584.

[43] E.I. Gürbüz, D.M. Alonso, J.Q. Bond, J.A. Dumesic, ChemSusChem, 4 (2011) 357-361.

[44] J.S. Luterbacher, J.M. Rand, D.M. Alonso, J. Han, J.T. Youngquist, C.T. Maravelias, B.F.

Pfleger, J.A. Dumesic, Science, 343 (2014) 277-280.

[45] R.S. Assary, L.A. Curtiss, J.A. Dumesic, ACS Catal., 3 (2013) 2694-2704.

[46] M. Boronat, A. Corma, M. Renz, J. Phys. Chem. B, 110 (2006) 21168-21174.

[47] A. Corma, L.T. Nemeth, M. Renz, S. Valencia, Nature, 412 (2001) 423-425.

[48] M. Boronat, P. Concepción, A. Corma, M. Renz, S. Valencia, J. Catal., 234 (2005) 111-118.

[49] S. Roy, K. Bakhmutsky, E. Mahmoud, R.F. Lobo, R.J. Gorte, ACS Catal., 3 (2013) 573-580.

[50] O.A. Abdelrahman, A. Heyden, J.Q. Bond, ACS Catal., 4 (2014) 1171-1181.

[51] P. Nandi, Y.I. Matvieiev, V.I. Boyko, K.A. Durkin, V.I. Kalchenko, A. Katz, J. Catal., 284 (2011) 42-49.

[52] Y.-P. Li, M. Head-Gordon, A.T. Bell, ACS Catal., 4 (2014) 1537-1545.

[53] R. Bermejo-Deval, R.S. Assary, E. Nikolla, M. Moliner, Y. Román-Leshkov, S.-J. Hwang, A. Palsdottir, D. Silverman, R.F. Lobo, L.A. Curtiss, Proc. Natl. Acad. Sci. U. S. A., 109 (2012) 97279732.

[54] C. Laurence, J.-F. Gal, Lewis basicity and affinity scales: Data and measurement, John Wiley \& Sons, 2009.

[55] C. Laurence, J. Graton, J.-F. Gal, J. Chem. Educ., 88 (2011) 1651-1657.

[56] P. Panagiotopoulou, N. Martin, D.G. Vlachos, J. Mol. Catal. A: Chem., 392 (2014) 223-228.

[57] J. Stelzer, M. Paulus, M. Hunger, J. Weitkamp, Microporous Mesoporous Mater., 22 (1998) 1-8.

[58] E.E. Mallon, I.J. Babineau, J.I. Kranz, Y. Guefrachi, J.I. Siepmann, A. Bhan, M. Tsapatsis, J. Phys. Chem. B, 115 (2011) 11431-11438.

[59] R. Gounder, M.E. Davis, AlChE J., 59 (2013) 3349-3358.

[60] R. Gounder, Catal. Sci. Technol., 4 (2014) 2877-2886. 


\section{Table 1}

Catalyst site and structural characterization.

\begin{tabular}{llll}
\hline Catalyst & $\mathrm{Si} / \mathrm{M}$ & $\begin{array}{l}\mathrm{V}_{\text {ads }}\left(\mathrm{N}_{2}\right)\left(\mathrm{cm}^{3} \mathrm{~g}^{-1}\right) \\
\text { micropore }\end{array}$ & $\begin{array}{l}\mathrm{V}_{\text {ads }}\left(\mathrm{N}_{2}\right)\left(\mathrm{cm}^{3} \mathrm{~g}^{-1}\right) \\
\text { total }\end{array}$ \\
\hline Ti-Beta & 108 & 0.20 & 0.33 \\
Hf-Beta & 121 & 0.20 & 0.30 \\
Zr-Beta & 111 & 0.20 & 0.29 \\
Sn-Beta & 108 & 0.20 & 0.34 \\
\hline
\end{tabular}

${ }^{[a]} \mathrm{N}_{2}$ volume at end of micropore filling transition $(77 \mathrm{~K})$ at $\mathrm{P} / \mathrm{P}_{\mathrm{o}}=0.01$

${ }^{[b]} \mathrm{N}_{2}$ volume at $\mathrm{P} / \mathrm{P}_{\mathrm{o}}=0.95$ 


\section{Table 2}

Measured first-order rate constants, activation energies and pre-exponential factors for MPV reduction of methyl levulinate (ML) in hydrogendonating solvent 2-butanol ( $\mathrm{BuOH}$ ) with various zeolite-beta catalysts. Rates are measured in moles of GVL produced per second normalized per total mole metal center in the catalyst. All liquid phase flow reactions were performed in a packed bed reactor pressurized under nitrogen at 20 bar with a flow rate range of $0.5-2.5 \mathrm{ml} / \mathrm{min}$, with temperature range of $393-453 \mathrm{~K}$.

\begin{tabular}{|c|c|c|c|c|c|c|c|c|}
\hline Run & Catalyst & Feed $\left(\mathrm{mol} \mathrm{dm}^{-3}\right)$ & Solvent & $\begin{array}{l}\text { Rate } \\
\text { constant } \\
\mathrm{k}_{\mathrm{app}} \text { at } 423 \\
\mathrm{~K}^{[\mathrm{a}]}\end{array}$ & 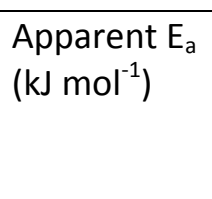 & $\begin{array}{l}\text { Standard } \\
\text { error }{ }^{[\mathrm{b}]} \\
\left(\mathrm{kJ} \mathrm{mol}^{-1}\right)\end{array}$ & $\begin{array}{l}\text { Pre-exponential } \\
\text { factor } A^{[c]}\end{array}$ & $\begin{array}{l}\text { Standard } \\
\text { multiplicative error } \\
{[b],[c]}\end{array}$ \\
\hline 1 & Hf-Beta & $0.02 \mathrm{ML}$ & $\mathrm{BuOH}$ & $1.33 \mathrm{E}+0$ & 52.5 & 1.9 & 41.3 & 1.7 \\
\hline 2 & Hf-Beta & $0.02 \mathrm{BuOH}$ & $M L$ & $1.10 \mathrm{E}-1^{[\mathrm{d}]}$ & 44.8 & 1.4 & $0.382^{[\mathrm{e}]}$ & 1.5 \\
\hline 3 & Zr-Beta & $0.02 \mathrm{ML}$ & $\mathrm{BuOH}$ & $6.84 \mathrm{E}-1$ & 51.8 & 1.0 & 17.3 & 1.3 \\
\hline 4 & Sn-Beta & $0.02 \mathrm{ML}$ & $\mathrm{BuOH}$ & $1.92 \mathrm{E}-1$ & 51.7 & 2.1 & 5.1 & 1.8 \\
\hline 5 & Ti-Beta & $0.02 \mathrm{ML}$ & $\mathrm{BuOH}$ & $5.26 \mathrm{E}-4$ & 69.0 & 2.2 & 1.8 & 1.9 \\
\hline
\end{tabular}

[a] units: $\left(\mathrm{mol} \mathrm{dm}^{3}\right)\left(\mathrm{mol}\right.$ metal*s*mol $\mathrm{ML}^{-1}$

[b] Standard error of regression assuming errors are normally distributed, sum of square residuals is $\chi^{2}$ distributed with $n-2$ degrees of freedom.

[c] units: $10^{5}\left(\mathrm{~mol} \mathrm{dm}^{3}\right)\left(\mathrm{mol}\right.$ metal*s*mol ML) ${ }^{-1}$

[d] units: $\left(\mathrm{mol} \mathrm{dm^{3 }}\right)\left(\mathrm{mol} \text { metal }{ }^{*}{ }^{*} \mathrm{~mol} \mathrm{BuOH}\right)^{-1}$

${ }^{\text {[e] }}$ units: $10^{5}\left(\mathrm{~mol} \mathrm{dm}^{3}\right)\left(\mathrm{mol} \text { metal }{ }^{*} \mathrm{~s}^{*} \mathrm{~mol} \mathrm{BuOH}\right)^{-1}$ 


\section{Table 3}

Measured first-order rate constants, activation energies and pre-exponential factors for MPV reduction of methyl levulinate (ML) in hydrogendonating solvents (BuOH, 2-butanol; 1-BuOH, 1-butanol; 2-PrOH, 2-propanol; 1-PrOH, 1-propanol; EtOH, ethanol; $\mathrm{Cy}$-PeOH, cyclopentanol) with $\mathrm{Hf}$-Beta catalyst. Rates are measured in moles of GVL produced per second normalized per total mole metal center in the catalyst. All liquid phase flow reactions were performed in a packed bed reactor pressurized under nitrogen at 20 bar with a flow rate range of 0.5-2.5 $\mathrm{ml} / \mathrm{min}$, with temperature range of 393-453 $\mathrm{K}$.

\begin{tabular}{|c|c|c|c|c|c|c|c|c|}
\hline Run & Catalyst & Feed $\left(\mathrm{mol} \mathrm{dm}^{-3}\right)$ & Solvent & $\begin{array}{l}\text { Rate } \\
\text { constant } \\
\mathrm{k}_{\mathrm{app}} \text { at } 423 \\
\mathrm{~K}^{[\mathrm{a}]}\end{array}$ & $\begin{array}{l}\text { Apparent } \mathrm{E}_{\mathrm{a}} \\
\left(\mathrm{kJ} \mathrm{mol}^{-1}\right)\end{array}$ & $\begin{array}{l}\text { Standard } \\
\text { error }{ }^{[\mathrm{b}]} \\
\left(\mathrm{kJ} \mathrm{mol}^{-1}\right)\end{array}$ & $\begin{array}{l}\text { Pre-exponential } \\
\text { factor } A^{[c]}\end{array}$ & $\begin{array}{l}\text { Standard } \\
\text { multiplicative error } \\
{[b],[c]}\end{array}$ \\
\hline 1 & Hf-Beta & $0.02 \mathrm{ML}$ & $\mathrm{BuOH}$ & $1.33 E+0$ & 52.5 & 1.9 & 41.3 & 1.7 \\
\hline 6 & Hf-Beta & $0.02 \mathrm{ML}$ & 1-BuOH & $1.64 \mathrm{E}-1$ & 73.5 & 4.4 & 1508.7 & 3.5 \\
\hline 7 & Hf-Beta & $0.02 \mathrm{ML}$ & 2-PrOH & $7.35 \mathrm{E}-1$ & 46.3 & 2.7 & 3.4 & 2.1 \\
\hline 8 & Hf-Beta & $0.02 \mathrm{ML}$ & 1-PrOH & $5.41 \mathrm{E}-2$ & 69.2 & 2.9 & 189.6 & 2.3 \\
\hline 9 & Hf-Beta & $0.02 \mathrm{ML}$ & $\mathrm{EtOH}$ & $1.44 \mathrm{E}-2$ & 70.2 & 4.2 & 68.8 & 3.3 \\
\hline 10 & Hf-Beta & $0.02 \mathrm{ML}$ & $\mathrm{Cy}-\mathrm{PeOH}$ & $1.96 \mathrm{E}-1$ & 56.9 & 2.2 & 20.6 & 1.9 \\
\hline
\end{tabular}

${ }^{[a]}$ units: $\left(\mathrm{mol} \mathrm{dm}^{3}\right)\left(\mathrm{mol} \mathrm{metal}^{*} \mathrm{~s}^{*} \mathrm{~mol} \mathrm{ML}\right)^{-1}$

${ }^{[b]}$ Standard error of regression assuming errors are normally distributed, sum of square residuals is $\chi^{2}$ distributed with $\mathrm{n}-2$ degrees of freedom.

[c] units: $10^{5}\left(\mathrm{~mol} \mathrm{dm}^{3}\right)\left(\mathrm{mol} \mathrm{metal}^{*} \mathrm{~s}^{*} \mathrm{~mol} \mathrm{ML}\right)^{-1}$ 

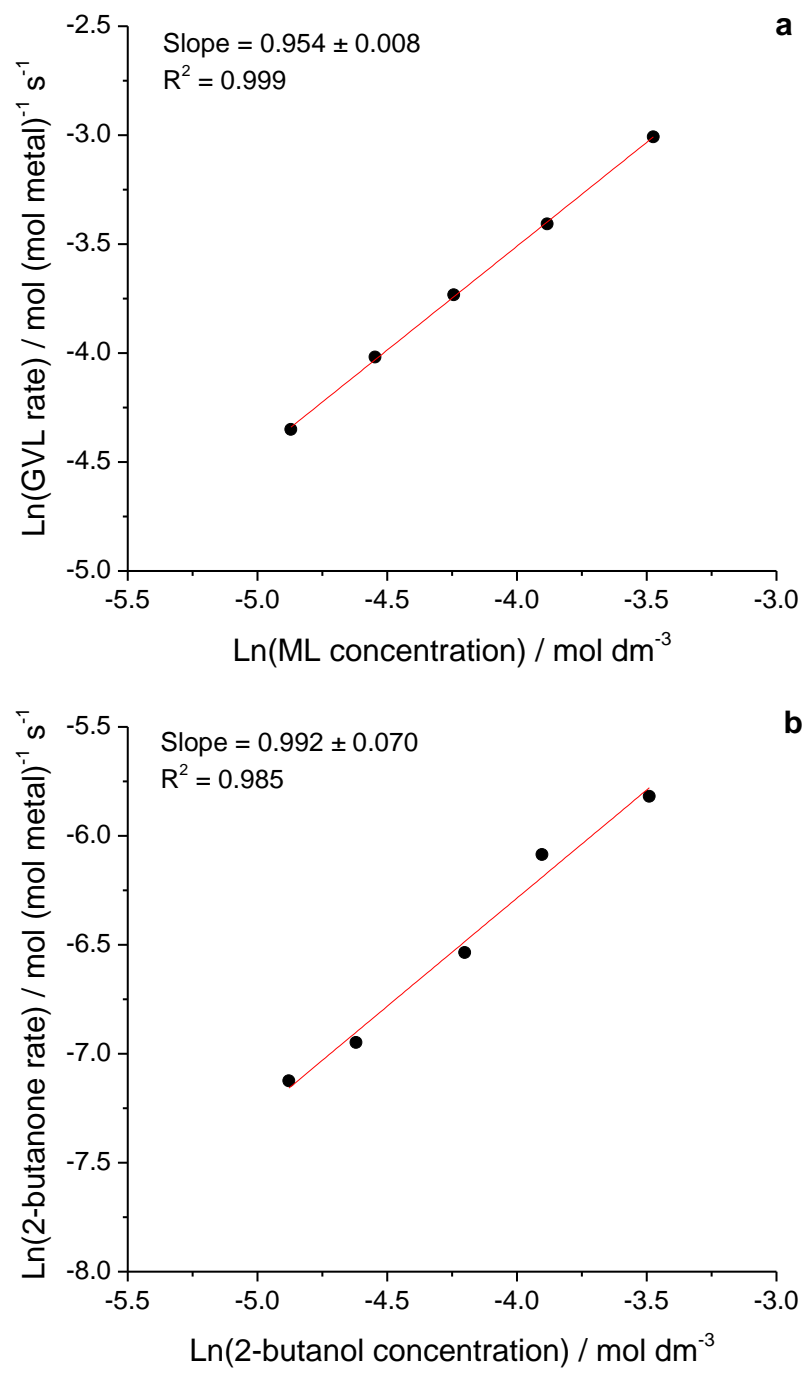

Figure 1. Log-log plot of initial rates vs methyl levulinate $(\mathrm{ML})$ concentration in solvent excess of 2butanol $(\mathrm{BuOH})(\mathrm{a})$, and $\mathrm{BuOH}$ concentration in solvent excess of $\mathrm{ML}$ (b) for Hf-Beta catalyst. Rates are measured in moles of GVL produced per second normalized per total mole metal center in the catalyst. In excess $M L$, rates are measured in moles of 2-butanone produced per second normalized per total metal center in the catalyst. The standard error of regression is calculated assuming errors are normally distributed and the sum of square residuals is $\chi^{2}$ distributed with $n-2$ degrees of freedom. All liquid phase flow reactions were performed under differential conditions in a packed bed reactor pressurized under nitrogen at 15 bar with a flow rate of $1.0 \mathrm{ml} \mathrm{min}^{-1}$, at temperature $423 \mathrm{~K}$, with feed concentrations of 0.0075-0.03 mol dm $\mathrm{m}^{-3}$ reactant. 


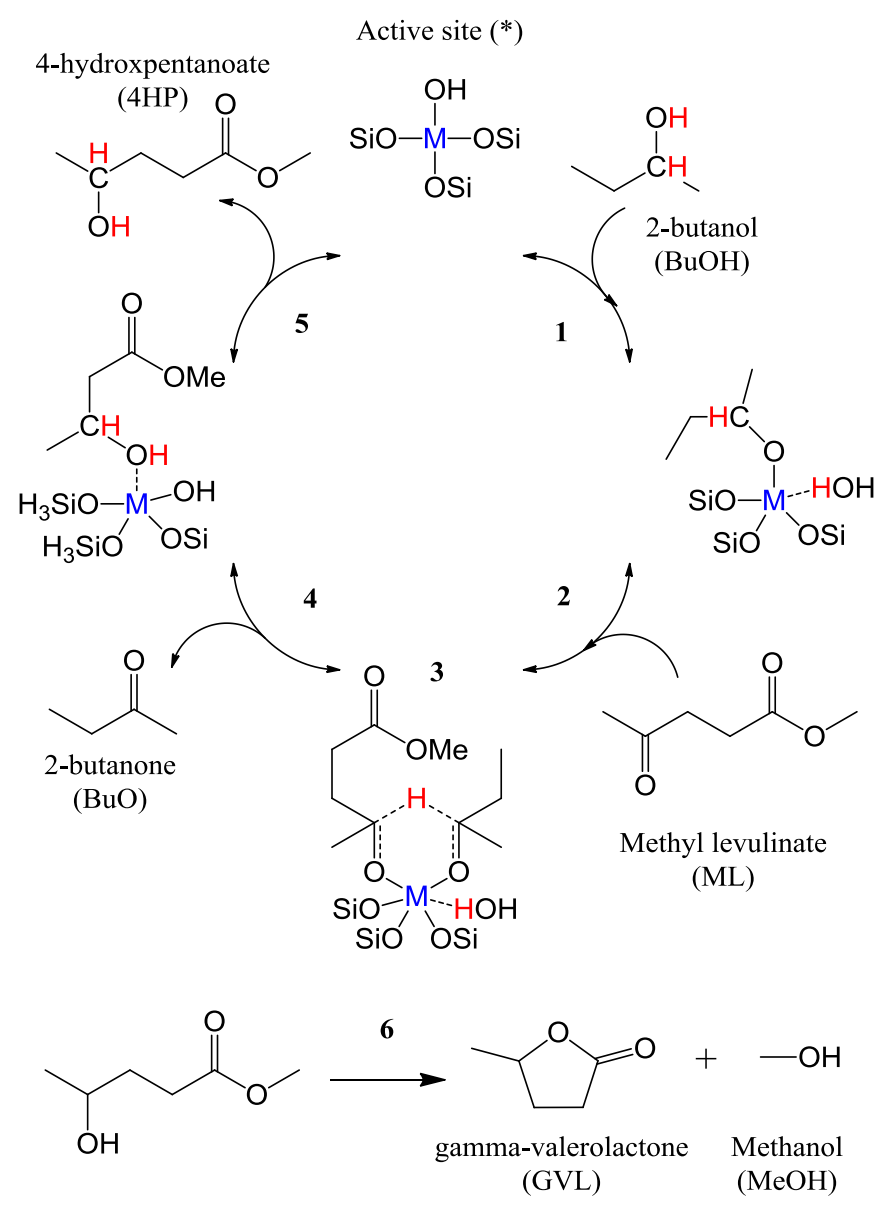

Scheme 1. Proposed catalytic cycle for the MPV reduction of methyl levulinate (ML) to 4hydroxypentanoate (4HP) with 2-butanol $(\mathrm{BuOH})$ over a partially hydrolyzed metal site in zeolite framework (*). BuOH adsorbs and deprotonates (1), ML then adsorbs (2) and converts to 4HP through a hydride shift in a six-membered transition state (3), 2-butanone (BuO) desorbs (4), 4HP receives a proton from the catalyst and desorbs (5), and 4HP undergoes spontaneous lactonization producing GVL and methanol $(\mathrm{MeOH})(6)$. 


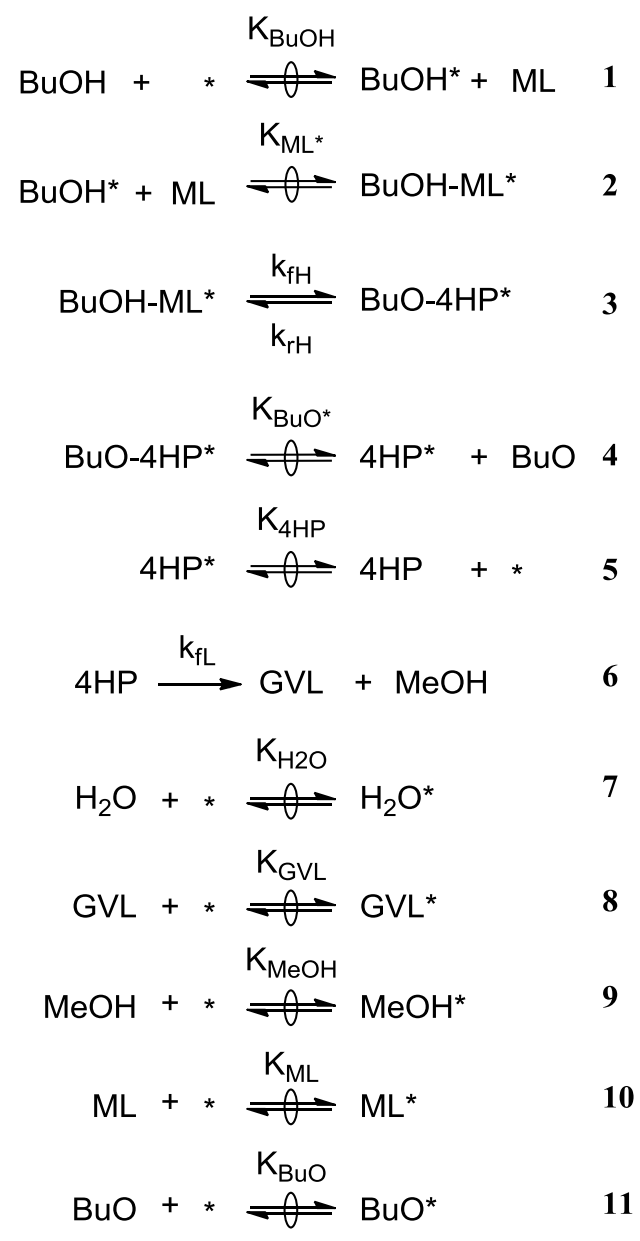

Scheme A2. Proposed elementary steps for the catalytic cycle of the MPV reduction of methyl levulinate $(\mathrm{ML})$ to 4-hydroxypentanoate (4HP) with 2-butanol $(\mathrm{BuOH})$ over a partially hydrolyzed metal site in zeolite framework $(*)$. Singly bound species can reversibly deactivate the catalytic site as shown in equations steps 7-11. Doubly bound inhibitors are assumed to be negligible. 


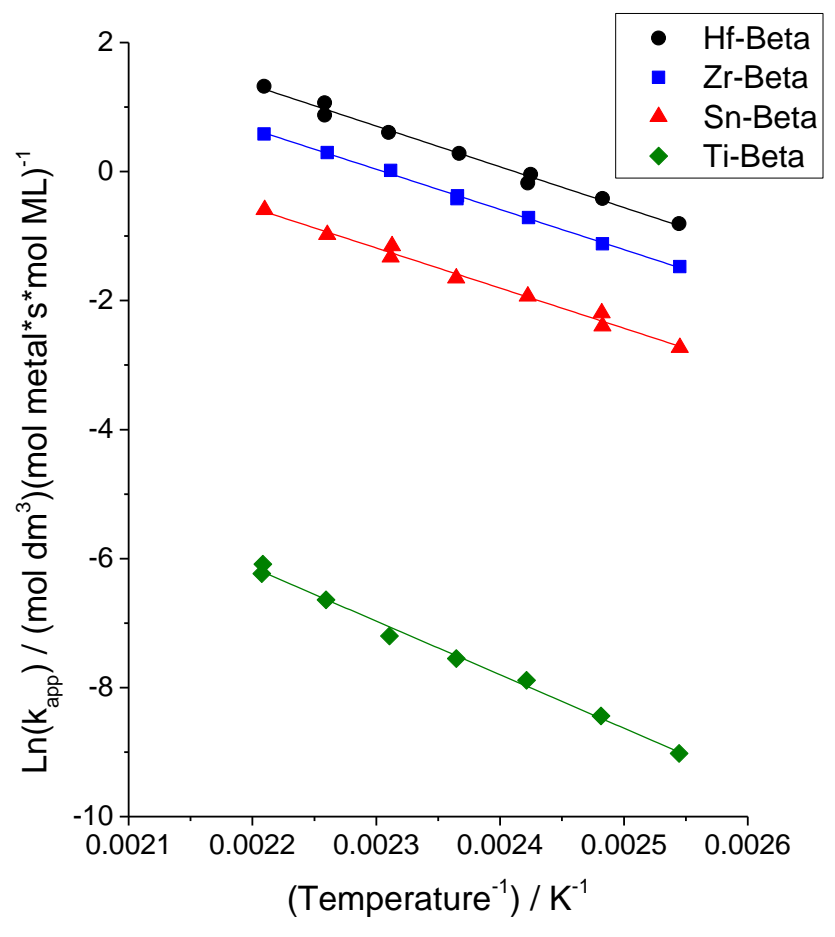

Figure 2. Arrhenius plot for the MPV reduction of $0.02 \mathrm{~mol} \mathrm{dm}^{-3} \mathrm{ML}$ in 2-butanol solvent with various zeolite-beta catalysts. Hf-Beta ( $\bullet$ ), Zr-Beta( $\boldsymbol{\square})$, Sn-Beta $(\Delta)$, Ti-Beta $(\diamond)$. Rates are measured in moles of GVL produced per second normalized per total mole metal center in the catalyst. All liquid phase flow reactions were performed under differential conditions in a packed bed reactor pressurized under nitrogen at 15 bar with a flow rate range of $0.5-2.5 \mathrm{ml} \mathrm{min}^{-1}$, with temperature range of 393-453 $\mathrm{K}$. 


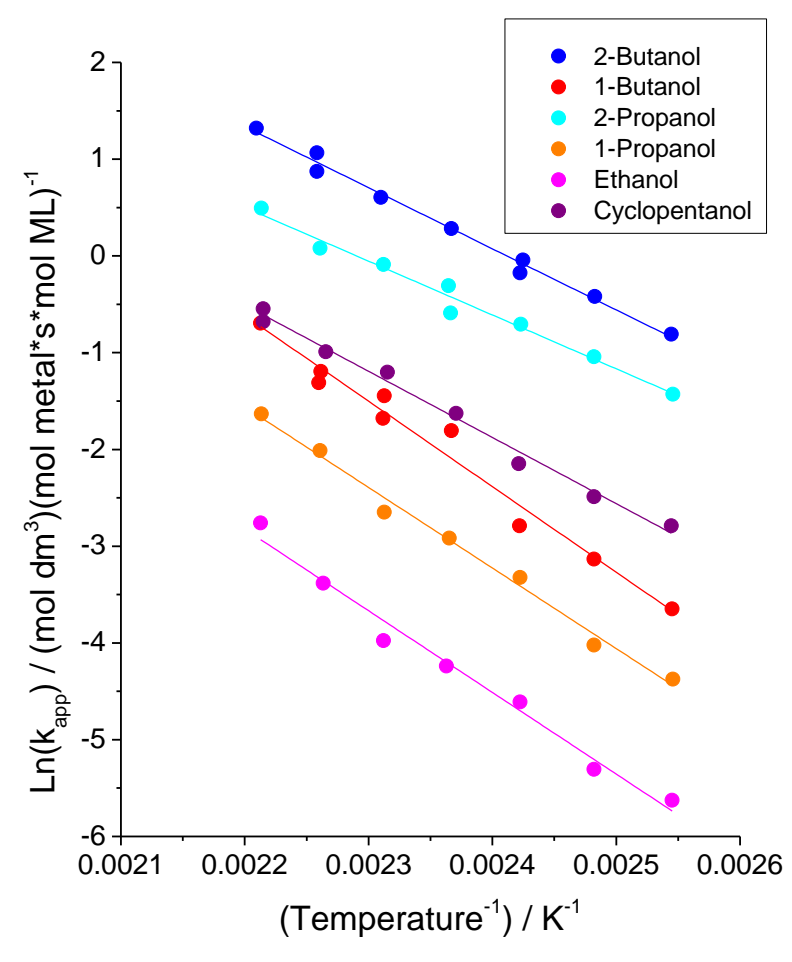

Figure 3. Arrhenius plot for the MPV reduction of ML with Hf-Beta using different hydrogen donors (BuOH, 2-butanol; 1-BuOH, 1-butanol; 2-PrOH, 2-propanol; 1-PrOH, 1-propanol; EtOH, ethanol; $\mathrm{Cy}-\mathrm{PeOH}$, cyclopentanol). $0.02 \mathrm{~mol} \mathrm{dm}^{-3} \mathrm{ML}$ in 2-BuOH (@), $0.02 \mathrm{~mol} \mathrm{dm}^{-3} \mathrm{ML}$ in $1-\mathrm{BuOH}(\bullet), 0.02 \mathrm{~mol} \mathrm{dm}^{-3} \mathrm{ML}$ in 2-PrOH ( ), $0.02 \mathrm{~mol} \mathrm{dm}^{-3} \mathrm{ML}$ in 1-PrOH ( ), $0.02 \mathrm{~mol} \mathrm{dm}^{-3} \mathrm{ML}$ in EtOH ( $\odot$ ), $0.02 \mathrm{~mol} \mathrm{dm}^{-3} \mathrm{ML}$ in Cy$\mathrm{PeOH}(\bullet)$. Rates are measured in moles of GVL produced per second normalized per total mole metal center in the catalyst. All liquid phase flow reactions were performed under differential conditions in a packed bed reactor pressurized under nitrogen at 21 bar with a flow rate range of $0.5-2.5 \mathrm{ml} \mathrm{min}{ }^{-1}$, with temperature range of 393-453 K. 


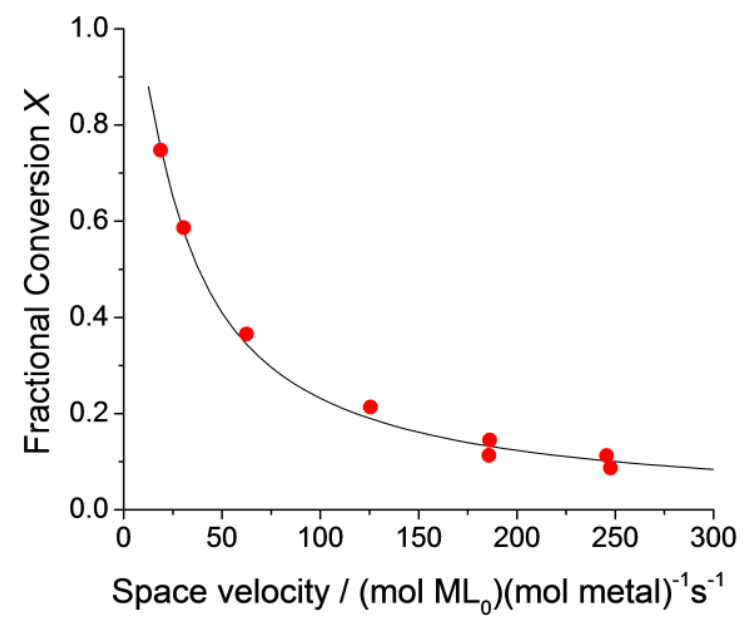

Figure 4. Comparison between experimental and model-predicted conversion of ML to GVL using 2butanol with $\mathrm{Hf}$-Beta catalyst at various space velocities. Liquid phase flow reactions were performed in a packed bed reactor pressurized under nitrogen at 15 bar with a flow rate range of $0.3-5.0 \mathrm{ml} \mathrm{min}{ }^{-1}$, $0.02 \mathrm{~mol} \mathrm{dm}^{-3} \mathrm{ML}$ at $423 \mathrm{~K}$. 